\title{
Estimasi Penyebaran Kanker Paru pada Bagian Tulang Belakang (Vertebra) dengan Menganalisis Nilai Uptake Te ${ }^{99 m}$ MDP
}

\author{
Chintia Rahmi Andriani, ${ }^{1,}$, Dian Milvita ${ }^{1}$, Fadil Nazir ${ }^{2}$ \\ ${ }^{1}$ Jurusan Fisika Universitas Andalas \\ ${ }^{2}$ PTKMR BATAN Jakarta \\ *chintiarahmi911@yahoo.com
}

\begin{abstract}
ABSTRAK
Telah dilakukan penelitian estimasi penyebaran kanker paru pada bagian tulang belakang (vertebra) dengan menganalisis nilai uptake $\mathrm{Tc}^{99 \mathrm{~m}}$ MDP. Data diperoleh dari 18 orang penderita kanker paru yang melakukan pemeriksaan bone scan. Pemeriksaan bone scan menggunakan bahan radiofarmaka $\mathrm{Tc}^{99 \mathrm{~m}}$ MDP yang diinjeksikan ke dalam tubuh. Pemeriksaan dilakukan di bawah kamera gamma secara spot static selama 30 menit pada posisi anterior dan posterior. Hasil citra pemeriksaan bone scan diolah dengan teknik ROI dengan fokus pada tulang belakang dan bagian sekitarnya. Hasil menunjukkan nilai uptake $\mathrm{Tc}^{99 \mathrm{~m}} \mathrm{MDP}$ pada bagian tulang belakang dan sekitarnya untuk setiap pasien kanker paru berbeda. Pasien dengan nilai uptake $\mathrm{Tc}^{99 \mathrm{~m}}$ MDP yang berada di atas 345609 count untuk posisi anterior dan 389457 count untuk posisi posterior mengalami metastasis, kecuali adanya kasus tertentu pada pasien. Nilai \% uptake $\mathrm{Tc}^{99 \mathrm{~m}}$ MDP tulang servikal, tulang torakal dan tulang lumbal secara rerata berbeda, baik pada posisi anterior maupun posisi posterior.

Kata kunci : tulang belakang, kanker paru, uptake $\mathrm{Tc}^{99 \mathrm{~m}} \mathrm{MDP}$
\end{abstract}

\section{ABSTRACT}

Research about estimation of the spreding of lung cancer in the spine by analysing with Tc ${ }^{99 m} M D P$ uptake has been done. Data was obtained from 18 lung cancer patients during a bone scan. The bone scan used Tc ${ }^{99 m}$ MDP that injected in to body. The scan was canducted using gamma camera, on the static spot for 30 minutes on anterior and posterior position. The bone scan images were prosessed using ROI techniques with focal at the spine and surrounding. The value of $T c^{99 m} M D P$ uptake for each patients are different. A patient with $T c^{99 m}$ MDP uptake higher than 345605 count on anterior position and on posterior position higher than 389457 count suffers a metastasis, except in certain cases pasient. The average percentace value of $T c^{99 m}$ MDP uptake for cervical, thoracic, and lumbar bunes are different on anterior and posterior position.

Keywords: spine, lung cancer, $T c^{99 m} M D P$ uptake, biodistribution $T c^{99 m} M D P$

\section{PENDAHULUAN}

Kanker paru merupakan kasus kanker yang sering terjadi di dunia dengan kejadian 1,2 juta kasus baru per tahun dan akan terus meningkat menjadi 12 juta kasus pada tahun 2030 (WHO, 2012). Kanker paru merupakan semua keganasan sel yang berada di paru, kanker ini dapat menyerang laki-laki maupun perempuan terutama yang berusia di atas 35 tahun. Menurut KEMENKES RI pada tahun 2015 dalam data GLOBOCAN (IARC) kanker paru merupakan penyebab kematian pertama di dunia untuk penduduk laki-laki. Kanker paru sering terlambat didiagnosis, sehingga lebih dari 50\% kanker telah menyebar ke seluruh tubuh terutama pada bagian tulang belakang, otak, hati dan kelenjar adrenal melalui aliran darah dan getah bening (Ismail, 2011). Tulang belakang merupakan bagian tubuh yang sangat penting dalam melakukan aktivitas sehari-hari, karena tulang belakang berfungsi sebagai penyokong tubuh dan pengendali gerak (Pearce, 2009).

Diagnosis penyebaran sel kanker paru pada bagian tulang dapat dilakukan dengan berbagai metode seperti CT-Scan toraks, MRI dan bone scan (Sudoyo, 2009). Metode CT-Scan toraks merupakan metode pencitraan yang memanfaatkan sinar-X dan MRI merupakan metode pencitraan yang memanfaatkan medan magnet, sedangkan bone scan merupakan pencitraan yang dilakukan dengan teknik kedokteran nuklir yang memanfaatkan kamera gamma dan bahan radiofarmaka.

Pada kedokteran nuklir, pemeriksaan dapat dilakukan dengan dua cara yaitu secara invivo dan in-vitro. In-vivo adalah penggunaan bahan radiofarmaka yang di masukan ke dalam tubuh, sedangkan in-vitro adalah penggunaan bahan radiofarmaka di luar tubuh. Pemeriksaan Bone scan merupakan pemeriksaan yang dilakukan secara in-vivo menggunakan sistem planar 
kamera gamma. Sistem planar adalah sistem pencitraan spot statikdan spot dinamik dengan detektor kamera gamma hanya dapat bergerak ke atas serta kebawah.Bahan radiofarmaka yang biasa digunakan pada pemeriksaan bone scan adalah $\mathrm{Tc}^{99 \mathrm{~m}}$ MDP. Aktivitas Tc ${ }^{99 \mathrm{~m}}$ MDP yang diberikan kepada pasien cukup tinggi sekitar 10-20 mCi atau sekitar 370-740 MBq (ICRP, 1988), sehingga diperlukan penelitian untuk menilai uptake dari radiofarmaka yang masuk ke dalam tulang. Uptake adalah kemampuan organ dalam menangkap radiofarmaka, dari nilai uptake dapat diketahui kelainan suatu organ. Uptake dapat diketahui dengan menggunakan teknik Region of Interest (ROI) yang ada pada komputer kamera gamma. ROI adalah perangkat lunak yang dapat menggambarkan jumlah cacahan yang ditangkap oleh kamera gamma. Penelitian yang dilakukan adalah estimasi penyebaran sel kanker paru pada bagian tulang belakang dengan menganalisis nilai uptake $\mathrm{Tc}^{99 \mathrm{~m}}$ MDP. Penelitian difokuskan pada bagian tulang belakang seluruhnya, tulang belakang cervikal/tulang leher, tulang belakang torak/tulang punggung, dan tulang belakang lumbal/tulang panggul serta bagian sekitarnya seperti leher, tulang dada dan abdomen. Penelitian ini penting dilakukan karena dari nilai uptake yang diperoleh akan diketahui data kuantitatif dari penyebaran sel kanker paru pada bagian tulang belakang dan akan diketahui nilai uptake tulang belakang normal.

\section{METODE}

Penelitian dilakukan di salah satu Rumah Sakit X di kota Jakarta selama 7 bulan, dengan sampel 18 orang penderita kanker paru yang melakukan pemeriksaan bone scan. Penelitian menggunakan radiofarmaka Tc ${ }^{99 m}$ MDP dan kamera gamma dual head secara spot static selama 30 menit. Pencitraan dihasilkan dalam posisi anterior dan posterior yang kemudian diolah menggunakan teknik ROI pada komputer proses data kamera gamma. ROI dibuat berbentuk kotak (box) sesuai dengan titik fokus yang ditentukan yaitu : tulang belakang seluruhnya, tulang servikal, tulang torakal, tulang lumbal, leher, tulang dada dan abdomen. Dari hasil ROI akan diperoleh nilai uptake dan \% uptake Tc ${ }^{99 \mathrm{~m}} \mathrm{MDP}$.

\section{HASIL DAN DISKUSI}

Dari 18 orang sampel, 15 orang diantaranya positif terdiagnosis menderita kanker paru dan 3 orang diantaranya negatif menderita kanker paru. Data yang diperoleh ditunjukkan pada Tabel 1.

Tabel 1 Data pasien kanker paru yang diperoleh

\begin{tabular}{|c|c|c|c|c|}
\hline No. & $\begin{array}{l}\text { Inisial } \\
\text { Pasien }\end{array}$ & $\begin{array}{c}\text { Jenis kelamin } \\
(\mathbf{P} / \mathbf{L})\end{array}$ & $\begin{array}{c}\text { Usia } \\
\text { (Tahun) }\end{array}$ & Diagnosis Awal \\
\hline 1. & YK & $\mathrm{L}$ & 44 & Kanker Paru \\
\hline 2. & $\mathrm{TN}$ & $\mathrm{L}$ & 65 & Kanker Paru \\
\hline 3. & MK & $\mathrm{L}$ & 62 & Tumor Paru Kanan \\
\hline 4. & EW & $\mathrm{L}$ & 58 & Kanker Paru \\
\hline 5. & $\mathrm{KM}$ & $\mathrm{P}$ & 44 & Kanker Paru \\
\hline 6. & UW & $\mathrm{L}$ & 33 & Kanker ParuKanan \\
\hline 7. & AW & $\mathrm{L}$ & 45 & Kanker Paru \\
\hline 8. & $\mathrm{NZ}$ & $\mathrm{P}$ & 40 & Kanker ParuKiri \\
\hline 9. & SH & $\mathrm{P}$ & 78 & Kanker Paru \\
\hline 10. & SE & $\mathrm{P}$ & 73 & Kanker Paru \\
\hline 11. & $\mathrm{JT}$ & $\mathrm{L}$ & 64 & Tumor Paru \\
\hline 12. & $\mathrm{NE}$ & $\mathrm{P}$ & 66 & Kanker ParuKanan \\
\hline 13. & BT & $\mathrm{L}$ & 63 & Kanker Paru \\
\hline 14. & LZ & $\mathrm{P}$ & 62 & Kanker Paru Kanan \\
\hline 15. & SS & $\mathrm{L}$ & 54 & Kanker ParuKanan \\
\hline 16. & KK & $\mathrm{P}$ & 67 & Kanker Paru \\
\hline 17. & SK & $\mathrm{L}$ & 73 & Tumor Paru Kanan \\
\hline 18. & $\mathrm{JH}$ & $\mathrm{L}$ & 41 & Kanker Paru \\
\hline \multicolumn{3}{|c|}{ Usia rata-rata } & 57 & \\
\hline \multicolumn{3}{|c|}{ Usia minimum } & 33 & \\
\hline \multicolumn{3}{|c|}{ Usia maksimum } & 78 & \\
\hline
\end{tabular}


Pada Tabel 1. Dapat dilihat bahwa penderita kanker paru memiliki rerata usia di atas 40 tahun. Usia merupakan faktor penting terjadinya kanker paru karena mempengaruhi kemampuan mekanisme perbaikan sel yang semakin menurun (Kumar dan Maitra, 2007). Namun, pada penelitian ini juga ditemukan penderita kanker paru yang berusia 33 tahun berinisial UM. UM berjenis kelamin laki-laki, didiagnosis dokter menderita kanker paru kanan. Menurut Ward pada tahun 2008, selain usia kanker paru juga dapat disebabkan oleh faktor lain seperti jenis kelamin, kebiasaan merokok atau akibat paparan zat karsinogen pada pekerja.

Diagnosis awal seperti yang terlihat pada Tabel 1 merupakan hasil kiriman dari dokter spesialis paru yang meminta agar dilakukan pemeriksaan bone scan di instalasi kedokteran nuklir. Pemeriksaan dilakukan untuk mengetahui adanya penyebaran (metastasis) sel kanker paru pada tulang.

\subsection{Nilai Uptake Tc $^{99 m}$ MDP pada Bagian Tulang Belakang Pasien Kanker Paru}

Nilai uptake $\mathrm{Tc}^{99 \mathrm{~m}}$ MDP pada bagian tulang belakang pasien kanker paru diperoleh dari pengolahan hasil pemeriksaan bone scan pada posisi anterior dan posterior dengan teknik ROI (Region of Interest) yang ada pada komputer pemproses data kamera gamma. Nilai uptake $\mathrm{Tc}^{99 \mathrm{~m}}$ MDP yang diperoleh memiliki satuan count (jumlah cacahan, contoh 1 kcount $=1000$ count). Nilai uptake $\mathrm{Tc}^{99 \mathrm{~m}}$ MDP pada setiap bagian tulang belakang dan bagian sekitarnya berbeda. Setiap masing-masing pasien juga memiliki nilai uptake $\mathrm{Tc}^{99 \mathrm{~m}}$ MDP yang berbeda-beda, bergantung dari kemampuan sel muda (sel osteoblast) menangkap radioaktivitas.

Nilai uptake $\mathrm{Tc}^{99 \mathrm{~m}}$ MDP setiap bagian tulang pada posisi anterior secara rerata untuk tulang belakang seluruhnya adalah 373188 count, tulang torakal 225288 count, tulang cervikal 81713 count dan tulang lumbal 72412 count. Pada posisi posterior, nilai uptake Tc ${ }^{99 m}$ MDP secara rerata untuk tulang belakang seluruhnya adalah 413552 count, tulang torakal 244234 count, tulang lumbal 104746 count dan tulang cervikal 66152 count. Pada tulang belakang keseluruhan, nilai uptake $\mathrm{Tc}^{99 \mathrm{~m}}$ MDP yang berada di atas 345609 count posisi anterior dan 389457 count posisi posterior mengalami metastasis. Sukandar (1982), menyebutkan semakin tinggi nilai uptake pada suatu organ maka terdapat kelainan pada organ tersebut. Peningkatan radiofarmaka yang tidak merata pada tulang menandakan adanya metastasis pada tulang tersebut (Fardela, 2011).

Nilai uptake $\mathrm{Tc}^{99 \mathrm{~m}}$ MDP tertinggi posisi anterior dan posterior terdapat pada pasien yang berinisial EW yaitu 574429 count dan 587319 count. Bagian tulang servikal EW memiliki nilai uptake $\mathrm{Tc}^{99 \mathrm{~m}}$ MDP yang tidak terlalu tinggi, sedangkan pada bagian tulang torakal dan tulang lumbal memiliki nilai uptake $\mathrm{Tc}^{99 \mathrm{~m}} \mathrm{MDP}$ yang lebih tinggi daripada pasien lainya. Tingginya serapan bahan radiofarmaka pada bagian tulang torakal dan tulang lumbal EW dapat disebabkan karena aktivitas radiofarmaka di daerah tersebut mengindikasikan adanya aktivitas sel osteoblast yang meningkat. Dari data yang diperoleh, EW merupakan seorang pasien yang merasakan keluhan nyeri tulang. Terdapat perbedaan persepsi antara dokter spesialis kedokteran nuklir dan penelitian ini. Jawaban dokter menyatakan bahwa EW tidak mengalami metastasis pada bagian tulang tersebut. Hasil penelitian menunjukkan tulang belakang EW menangkap lebih banyak bahan radiofarmaka. Perbedaan ini dapat disebabkan karena berbedanya cara penilaian hasil pemeriksaan bone scan yang diperoleh. Dokter menilai metastasis dengan gambar (visual) yang dihasilkan pada pemeriksaan bone scan, sedangkan pada penelitian ini menilai metastasis dengan nilai uptake $\mathrm{Tc}^{99 \mathrm{~m}}$ MDP sehingga dapat diketahui data kuantitatif pada tulang tersebut. Dari hasil penelitian disarankan pada kasus EW dilakukan penilaian secara kuantitatif lebih lanjut untuk memastikan adanya metastasis pada tulang belakang yang tidak terlihat secara visual.

Nilai uptake $\mathrm{Tc}^{99 \mathrm{~m}}$ MDP terendah pada tulang belakang terdapat pada pasien berinisial NZ. Nilai uptake Tc ${ }^{99 m}$ MDP pada posisi anterior adalah 283958 count dan posisi posterior adalah 265664 count. Pada bagian tulang servikal, tulang lumbal dan tulang torakal nilai uptake $\mathrm{Tc}^{99 \mathrm{~m}}$ MDP NZ yang diperoleh juga tidak terlalu tinggi. Dari hasil tersebut dapat diketahui bagian tulang belakang NZ tidak mengalami metastasis. NZ merupakan pasien yang telah mengalami metastasis kanker paru pada bagian tulang panggul. Pada penelitian ini tulang panggul tidak dijadikan titik fokus, sehingga data kuantitatif NZ pada bagian tersebut tidak 
diketahui. NZ melakukan pemeriksaan bone scan setiap 6 bulan untuk follow up terapi yang telah dilakukannya. Terapi yang dilakukan NZ mengurangi metastasis yang dialaminya, dengan ditandai kurangnya penangkapan radiofarmaka pada tulang atau kecilnya nilai uptake $\mathrm{Tc}^{99 \mathrm{~m}}$ MDP. Hal ini menandakan adanya respons baik dari hasil pengobatan yang telah dilakukan pasien berinisial NZ tersebut.

\subsection{Nilai \% Uptake Te ${ }^{99 \mathrm{~m}}$ MDP pada Bagian Tulang Belakang Pasien Kanker Paru}

Nilai \% uptake $\mathrm{Tc}^{99 \mathrm{~m}}$ MDP pada bagian tulang belakang, diperoleh dari pengolahan nilai uptake $\mathrm{Tc}^{99 \mathrm{~m}}$ MDP. Nilai \% uptake $\mathrm{Tc}^{99 \mathrm{~m}}$ MDP yang ditentukan adalah tulang servikal, tulang torakal dan tulang lumbal baik pada posisi anterior maupun posterior. Nilai\% uptake $\mathrm{Tc}^{99 \mathrm{~m}}$ MDP bagian tulang ditentukan dengan dua cara yaitu antara seluruh tulang belakang dengan bagian-bagian tulang yaitu tulang servikal, tulang torakal dan tulang lumbal serta antara tulang servikal dengan leher, tulang torakal dengan tulang dada dan tulang lumbal dengan abdomen.

Tabel 2 Nilai \% uptake $\mathrm{Tc}^{99 \mathrm{~m}}$ MDP antara tulang belakang dengan bagian tulang servikal, tulang torakal dan tulang lumbal

\begin{tabular}{|c|c|c|c|c|c|c|c|}
\hline \multirow[b]{2}{*}{ No. } & \multirow[b]{2}{*}{ Nama } & \multicolumn{3}{|c|}{$\begin{array}{l}\text { Nilai \% uptake pada posisi } \\
\text { Posterior }\end{array}$} & \multicolumn{3}{|c|}{$\begin{array}{c}\text { Nilai \% uptake pada posisi } \\
\text { Anterior }\end{array}$} \\
\hline & & $\begin{array}{c}\% \\
\text { Tulang } \\
\text { servikal }\end{array}$ & $\begin{array}{l}\text { \% Tulang } \\
\text { Torakal }\end{array}$ & $\begin{array}{c}\% \\
\text { Tulang } \\
\text { Lumbal }\end{array}$ & $\begin{array}{l}\text { \% Tulang } \\
\text { servikal }\end{array}$ & $\begin{array}{c}\text { \% Tulang } \\
\text { Torakal }\end{array}$ & $\begin{array}{c}\text { \% Tulang } \\
\text { Lumbal }\end{array}$ \\
\hline 1. & YK & 12,58 & 65,63 & 24,93 & 17,22 & 63,58 & 19,73 \\
\hline 2. & $\mathrm{TN}$ & 16,60 & 60,35 & 23,92 & 25,84 & 62,00 & 14,23 \\
\hline 3. & MK & 14,43 & 60,05 & 25,78 & 20,51 & 61,44 & 20,57 \\
\hline 4. & EW & 13,57 & 61,83 & 25,76 & 18,00 & 59,80 & 24,37 \\
\hline 5. & $\mathrm{KM}$ & 14,25 & 62,29 & 24,59 & 21,63 & 62,21 & 17,61 \\
\hline 6. & UW & 14,86 & 60,48 & 26,60 & 18,59 & 61,70 & 21,51 \\
\hline 7. & AW & 13,95 & 61,82 & 25,89 & 18,05 & 62,44 & 21,17 \\
\hline 8. & $\mathrm{NZ}$ & 21,02 & 54,16 & 23,97 & 25,44 & 56,60 & 17,77 \\
\hline 9. & SH & 20,80 & 54,85 & 20,30 & 26,42 & 55,45 & 13,61 \\
\hline 10. & $\mathrm{SE}$ & 15,76 & 54,86 & 29,37 & 25,49 & 61,13 & 14,34 \\
\hline 11. & $\mathrm{JT}$ & 18,57 & 57,02 & 26,72 & 25,84 & 59,33 & 16,76 \\
\hline 12. & $\mathrm{NE}$ & 19,81 & 58,84 & 21,14 & 22,47 & 58,74 & 19,62 \\
\hline 13. & BT & 19,37 & 60,13 & 20,88 & 24,25 & 61,84 & 15,54 \\
\hline 14. & LZ & 23,06 & 53,12 & 21,73 & 27,21 & 55,63 & 15,53 \\
\hline 15. & SS & 14,40 & 60,68 & 25,11 & 20,09 & 57,17 & 22,85 \\
\hline 16. & KK & 12,69 & 58,15 & 29,14 & 23,32 & 52,23 & 24,43 \\
\hline 17. & SK & 15,46 & 58,00 & 26,52 & 18,63 & 62,50 & 18,86 \\
\hline 18. & $\mathrm{JH}$ & 8,52 & 61,13 & 30,34 & 12,43 & 62,69 & 24,87 \\
\hline \multicolumn{2}{|c|}{ Rata-rata } & 16,09 & 59,08 & 25,15 & 21,75 & 59,80 & 19,08 \\
\hline
\end{tabular}

Berdasarkan Tabel 2, rerata \% uptake $\mathrm{Tc}^{99 \mathrm{~m}}$ MDP tulang servikal dan torakal posisi posterior lebih kecil jika dibandingkan dengan posisi anterior. Pada tulang lumbal, posisi posterior lebih besar dari pada anterior yaitu $25,15 \%$ posterior dan $19,08 \%$ anterior. Perbedaan ini dapat disebabkan pada posisi posterior tulang lumbal sangat dekat dengan detektor kamera gamma. Selanjutnya pada posisi anterior, tulang lumbal letaknya lebih jauh ke detektor kamera gamma, sehingga akan ada atenuasi atau halangan dari berbagai organ kearah anterior. Secara keseluruhan, antara anterior dan posterior \% uptake $\mathrm{Tc}^{99 \mathrm{~m}} \mathrm{MDP}$ dapat dipengaruhi oleh berbagai organ yang berada di depan tulang. Selain itu, jarak dan pengambilan ukuran ROI serta bentuk ROI yang digunakan juga memegang peran penting dalam menilai \% uptake $\mathrm{Tc}^{99 \mathrm{~m}} \mathrm{MDP}$. 
Nilai \% uptake $\mathrm{Tc}^{99 \mathrm{~m}}$ MDP setiap bagian tulang belakang juga dapat ditentukan dengan nilai uptake $\mathrm{Tc}^{99 \mathrm{~m}}$ MDP bagian sekitarnya, baik pada posisi anterior maupun pada posisi posterior. Nilai \% uptake $\mathrm{Tc}^{99 \mathrm{~m}} \mathrm{MDP}$ pada setiap bagian tulang pasien kanker paru dapat dilihat pada Tabel 3. BerdasarkanTabel 3 pada posisi anterior nilai $\%$ uptake Tc ${ }^{99 m}$ MDP tulang servikal lebih besar daripada tulang torakal dan tulang lumbal. Pada posisi posterior, nilai \% uptake $\mathrm{Tc}^{99 \mathrm{~m}}$ MDP tulang servikal lebih besar daripada tulang torakal maupun tulang lumbal. Nilai \% uptake $\mathrm{Tc}^{99 \mathrm{~m}}$ MDP tulang lumbal lebih besar daripada tulang torakal baik pada posisi anterior maupun posterior. Rerata nilai \% uptake $\mathrm{Tc}^{99 \mathrm{~m}}$ MDP pada posisi anterior dan posterior menunjukkan hasil yang sama, nilai \% uptake $\mathrm{Tc}^{99 \mathrm{~m}}$ MDP teringgi adalah tulang servikal, tulang lumbal dan tulang torakal. Hal ini dapat disebabkan oleh adanya kasus-kasus penyebaran sel kanker paru pada bagian tulang tersebut. Dari diagnosis dokter spesialis kedokteran nuklir menunjukkan terjadi banyak kasus metastasis khususnya bagian tulang lumbal, sedangkan pada tulang servikal hasil dioagnosis dokter menyebutkan metastasis belum terlihat secara visual. Selain penyebaran sel kanker paru, hal tersebut dapat terjadi jika tulang mengalami suatu proses penyembuhan seperti fraktur (patah tulang) atau proses degeneratif.

Tabel 3 Nilai \% uptake Tc ${ }^{99 m}$ MDP antara bagian tulang dengan bagian sekitarnya

\begin{tabular}{|c|c|c|c|c|c|c|c|}
\hline \multirow[b]{2}{*}{ No. } & \multirow[b]{2}{*}{ Nama } & \multicolumn{3}{|c|}{$\begin{array}{l}\text { Nilai \% uptake pada posisi } \\
\text { Posterior }\end{array}$} & \multicolumn{3}{|c|}{$\begin{array}{c}\text { Nilai \% uptake pada posisi } \\
\text { Anterior }\end{array}$} \\
\hline & & $\begin{array}{c}\% \\
\text { Tulang } \\
\text { servikal }\end{array}$ & $\begin{array}{c}\% \\
\text { Tulang } \\
\text { Torakal }\end{array}$ & $\begin{array}{c}\% \\
\text { Tulang } \\
\text { Lumbal }\end{array}$ & $\begin{array}{c}\text { \% Tulang } \\
\text { servikal }\end{array}$ & $\begin{array}{l}\text { \% Tulang } \\
\text { Torakal }\end{array}$ & $\begin{array}{c}\text { \% Tulang } \\
\text { Lumbal }\end{array}$ \\
\hline 1. & YK & 70,07 & 39,28 & 65,19 & 63,29 & 36,44 & 54,74 \\
\hline 2. & $\mathrm{TN}$ & 70,57 & 36,56 & 62,68 & 71,74 & 36,48 & 54,87 \\
\hline 3. & MK & 74,00 & 39,55 & 61,35 & 78,67 & 36,49 & 59,79 \\
\hline 4. & EW & 70,31 & 41,30 & 63,93 & 71,37 & 39,62 & 62,29 \\
\hline 5. & KM & 68,93 & 39,78 & 61,89 & 68,97 & 35,94 & 58,81 \\
\hline 6. & UW & 77,99 & 42,44 & 66,81 & 75,65 & 40,53 & 63,13 \\
\hline 7. & AW & 76,69 & 40,37 & 47,59 & 77,42 & 37,90 & 46,74 \\
\hline 8. & $\mathrm{NZ}$ & 76,84 & 36,52 & 47,80 & 78,92 & 37,48 & 46,13 \\
\hline 9. & $\mathrm{SH}$ & 64,71 & 32,31 & 44,55 & 73,04 & 37,79 & 54,14 \\
\hline 10. & SE & 76,91 & 47,60 & 71,28 & 75,89 & 44,33 & 56,54 \\
\hline 11. & $\mathrm{JT}$ & 66,24 & 39,31 & 56,53 & 67,38 & 37,75 & 47,58 \\
\hline 12. & $\mathrm{NE}$ & 73,12 & 40,11 & 53,10 & 67,14 & 38,00 & 52,97 \\
\hline 13. & $\mathrm{BT}$ & 72,53 & 43,22 & 58,50 & 72,06 & 41,62 & 54,11 \\
\hline 14. & $\mathrm{LZ}$ & 75,59 & 39,95 & 74,78 & 52,01 & 40,02 & 73,48 \\
\hline 15. & SS & 68,77 & 41,46 & 60,07 & 66,76 & 37,94 & 63,73 \\
\hline 16. & $\mathrm{KK}$ & 62,94 & 37,34 & 78,17 & 71,71 & 30,67 & 70,97 \\
\hline 17. & SK & 66,01 & 32,07 & 67,98 & 65,78 & 36,24 & 64,22 \\
\hline 18. & $\mathrm{JH}$ & 65,66 & 33,91 & 74,18 & 64,36 & 28,13 & 69,15 \\
\hline \multicolumn{2}{|c|}{ Rata-rata } & 70,99 & 39,06 & 62,02 & 70,12 & 37,41 & 58,52 \\
\hline
\end{tabular}

\section{KESIMPULAN}

Nilai uptake $\mathrm{Tc}^{99 \mathrm{~m}}$ MDP pada bagian tulang belakang dan sekitarnya untuk setiap pasien kanker paru berbeda. Nilai uptake $\mathrm{Tc}^{99 \mathrm{~m}}$ MDP yang berada di atas 345609 count posisi anterior dan 389457 count posisi posterior mengalami metastasis, kecuali adanya kasus tertentu pada pasien. Nilai \% uptake Tc ${ }^{99 \mathrm{~m}}$ MDP tulang servikal, tulang torakal dan tulang lumbal secara rerata berbeda, baik pada posisi anterior maupun posisi posterior. 


\section{DAFTAR PUSTAKA}

Fardela, R., 2011, Penentuan Akumulasi Technetium-99 Metastabil Methylene Diphosphonat ( $\left.\mathrm{Tc}^{99 \mathrm{~m}} \mathrm{MDP}\right)$ Menggunakan Teknik ROI pada Tulang Panggul KiriDari Pasien Kanker Prostat, Skripsi, Fisika, Universitas Andalas, Padang.

Ilham, F.A., dan Milvita, D., 2015, Analisis Biodistribusi Tc ${ }^{99 m}$ Perteknetat pada Kelenjar Tiroid dan Kelenjar Ludah Pasien Struma Uni Nodosa dan Struma Multi Nodosa, Jurnal Fisika Unand, Volume 4, Nomor 4, Jurusan Fisika Unand, Hal 321-324.

ICRP, 1988,Radiation Dose to Patients From Radiopharmaceuticals, Publication No.53, Oxford, Inggris.

Kemenkes, RI., 2015, Stop Kanker,Infodatin,Kemenkes RI, Jakarta.

Kumar, V., dan Maitra, A., 2007, Paru dan Saluran Napas Atas, EGC, Jakarta.

Nuraini, P., 2011, Faktor Risiko Kanker Paru di RSUP Persahabatan Jakarta Tahun 2009-2010, skripsi, Pendidikan Kedokteran, Universitas Islam Negeri Syarif Hidayatullah, Jakarta.

Pearce, E.C., 2009, Anatomi dan Fisiologi untuk Para Medis, Gramedia, Jakarta.

Sudoyo, 2009, Buku Ajar Ilmu Penyakit Dalam, FKUI, Jakarta.

Sukandar,E., 1982, Bunga Rampai Ilmu Kedokteran, Alumni, Bandung.

Ward J., 2008, At a Glance Sistem Respirasi Wiener, Erlangga, Jakarta.

Ismail D., 2011, Harapan Baru untuk Penderita Kanker Paru, Harian Joglo Semar, http://harianjoglosemar.com/berita/harapan-baru-untuk-penderita-kankerparu49728.html, di akses tanggal 2 januari 2016

WHO., 2012, Statistik Kesehatan Dunia, http://www.who.int/gho/publications /world_health _statistics., di akses tanggal 2 januari 2016. 